\title{
A randomised controlled trial of the effect of hormone replacement therapy on disease activity in postmenopausal rheumatoid arthritis
}

\author{
G M Hall, M Daniels, E C Huskisson, T D Spector
}

\begin{abstract}
Objective-To assess the effects of hormone replacement therapy (HRT) on disease activity in postmenopausal rheumatoid arthritis (RA).

Methods-Two hundred postmenopausal outpatients (aged 45-65 years) were admitted into a single blind randomised placebo controlled trial of transdermal oestradiol (50 $\mu \mathrm{g}$ daily) over six months. Patients continued with routine antirheumatic medications. Compliance with HRT was monitored using serum oestradiol (E2) levels. Disease activity was monitored at entry, three and six months using erythrocyte sedimentation rate (ESR), articular index (AI), visual analogue pain scale (VPS) and early morning stiffness (EMS).
\end{abstract}

Results-Ninety one and 77 patients completed six months treatment with placebo and HRT respectively. There were no significant differences in baseline characteristics between the groups and no overall effects of treatment. However, 35 patients $(41 \cdot 6 \%)$, who completed HRT, failed to achieve serum E2 levels $>100$ pmol/l at either three or six months and were considered 'poor-compliers'. In the remaining HRT 'compliers' $(58 \cdot 4 \%)$ there were significant improvements after six months in articular index $(28.9 \% ; p<0.01)$ and pain score $(21.7 \% ; p<0.05)$ compared with placebo, as well as reductions in ESR $(8.9 \%$; NS) and morning stiffness $(25 \cdot 2 \%$; NS). Comparisons between HRT 'compliers' and 'poor-compliers' confirmed significant improvements in articular index $(p<0.001)$, pain score $(p<0.05)$ and morning stiffness $(p<0.001)$ in the 'compliers'.

Conclusions-This study did not show an overall effect of HRT on disease activity when used as an adjunct therapy in postmenopausal patients. A subgroup of patients, who had greater increments in serum E2 whilst taking HRT, demonstrated improvements in some parameters of disease activity, suggesting a potential beneficial effect with good compliance and higher dose HRT. Most importantly, in the treatment of $R A$ associated bone loss, HRT can be prescribed without fear of a disease flare up.

(Ann Rheum Dis 1994; 53: 112-116)
There has been considerable interest recently in the possible beneficial effects of exogenous oestrogens in rheumatoid arthritis (RA). This has mainly stemmed from the observations of the improvement of RA during pregnancy, ${ }^{1-3}$ the probable protective or disease modifying effect of the oral contraceptive pill ${ }^{4}$ and long term outcome studies suggesting that women fare worse than men, particularly after the menopause..$^{5-7}$ In experimental models oophorectomy will exacerbate collagen II induced arthritis in mice whilst oestrogens suppress its activity. ${ }^{8-9}$ There is evidence that oestrogens affect $T$-cell function as well as depressing the activity of the pro-inflammatory cytokine IL-1. ${ }^{10-12}$ These observations and others point towards a potential beneficial effect of hormone replacement therapy (HRT) in RA. Early studies of sex hormone therapy for arthritis in the 1930 s were encouraging ${ }^{13-14}$ but later results in the $1960 \mathrm{~s}$, using high doses, were less positive and reported numerous side effects. ${ }^{15-16}$ More recently, a small cross over study of 10 patients with RA treated with ethinyloestradiol for 12 weeks found improvement in walking time and number of swollen joints ${ }^{17}$ but another double blind study of 40 patients was negative. ${ }^{18}$

A single blind randomised study has been established to assess the effect of HRT in RA on: (1) bone mass over two years, and (2) disease activity over six months. The following report details the latter aspect of this study.

\section{Patients and methods}

PATIENTS

A total of 346 patients with RA (graded according to the 1987 ARA criteria) who were attending clinics from five centres in north east London, were invited by post to participate in a study of osteoporosis. Ethical approval was obtained from each centre. Patients (aged 48-65 years) were interviewed and recruited having satisfied the inclusion criteria: >three years since last menstrual period or $\mathrm{FSH}>15 \mathrm{iu} / \mathrm{l}$, and no contraindications to HRT. Patients who had started on a slow acting anti-rheumatic drug (SAARD) or glucocorticoid therapy within the previous three months were excluded. Patients were informed of the effects of HRT and calcium on bone metabolism but not of any possible effect on disease activity. Of those patients who replied, $227(65 \cdot 5 \%)$ were consecutively interviewed, and of these 27 were 
excluded. One hundred and thirty two (66\%) of the final cohort of 200 patients were taking slow acting anti-rheumatic drugs (SAARDS; penicillamine, sulphasalazine, gold, methotrexate, azathioprine or combination). Forty two patients $(21 \%)$ were taking a stable dose of glucocorticoids.

\section{TREATMENT}

Two hundred patients were allocated by block randomisation using random number tables to receive either transdermal oestradiol $50 \mu \mathrm{g}$ daily with oral norethisterone $1 \mathrm{mg}$ daily for 12 days per month (Estrapak 50 or Estraderm 50 if hysterectomised) or placebo (Sandocal 400, one tablet daily, providing $400 \mathrm{mg}$ calcium and considered inert in the context of a disease modifying agent). Trial therapy supplemented any existing medications taken for RA. Six patients had patch induced urticaria and HRT was altered to an oral form (Prempak-C 0.625 $\mathrm{mg}$ or Premarin $0.625 \mathrm{mg}$ daily). Five patients complained of premenstrual symptoms and treatment was successfully changed to a transdermal patch with dydrogesterone $10 \mathrm{mg}$ twice daily for 12 days of each month. One patient underwent hysterectomy and changed to transdermal patch only. Regular medication for RA could be altered at the clinician's discretion (not the investigator). Fifty three $(68.8 \%)$ patients who were allocated to HRT were receiving a SAARD and $57(62.6 \%)$ of those allocated to placebo.

\section{ASSESSMENTS}

Patients were assessed by the same observer who was 'blind' to treatment at entry, and at three and six months. Measured parameters of disease activity included early morning stiffness (EMS), Ritchie articular index (AI), a $10 \mathrm{~cm}$ visual analogue pain scale (VPS) and ESR. At three and six months, patients also completed a visual analogue improvement scale (VIS, $-5-+5 \mathrm{cms})$. A Health Assessment Questionnaire (HAQ) was completed at entry for group comparison. Serum oestradiol (E2) levels were measured at entry, and at three and six months using radioimmunoassay, and this helped to provide an assessment of patient compliance.

\section{STATISTICS AND ANALYSIS}

It was estimated that 100 patients in each group (allowing for withdrawals) was sufficient to detect a difference of treatment on disease activity at the $5 \%$ level with $80 \%$ power. The primary analyses were performed on patients who completed six months of the study. Intention to treat analysis was also performed. Efficacy analyses used Student's $t$ test for comparisons between patients completing placebo and HRT arms at three and six months. Analyses were performed on individual responses to treatment. Baseline data comparisons were made by $\mathrm{X}^{2}$ and unpaired $t$ test after $\log$ transformation on nonnormal data.

\section{Results}

Ninety one and 77 patients completed placebo and HRT, respectively, and patient characteristics are listed in table 1 . There were no differences between the two groups in age, menopausal years and disease duration. Patients allocated to HRT were significantly lighter $(63.1 v 67.4 \mathrm{~kg}, \mathrm{p}=0.01)$ but baseline E2 levels were similar in both groups. Patients receiving placebo reported a higher EMS score $(p=0.02)$ but other parameters of disease activity were similar. Thirty two patients failed to complete six months of treatment; 23 in the HRT arm and nine patients in the placebo arm (table 2). There were no significant differences in baseline characteristics between those who completed and those who withdrew from the study.

There were no significant differences in changes of disease activity parameters comparing the two groups overall, (table 3 ).

Two pharmacokinetic studies have shown that, using the HRT delivery system described, a mean steady state serum concentration of between 122 (SE 27) and 138 (SE 10) pmol/ 1 can be expected. ${ }^{19} 20$ However, only 42 $(58.4 \%)$ or the HRT group had E2 levels greater than $100 \mathrm{pmol} / \mathrm{l}$ at either three or six months and this subgroup of patients (termed 'compliers') was analysed separately from patients with E2 levels lower than $100 \mathrm{pmol} /$ 1 at three and six months ('poor compliers', 35 patients, $41 \cdot 6 \%$ ). Mean E2 levels at three and six months were $224 \cdot 1$ and $194.3 \mathrm{pmol} / \mathrm{l}$, respectively, in the 'compliers' and 40.0 and $45.2 \mathrm{pmol} / 1$ in the 'poor compliers'. There were no differences in characteristics between 'compliers' and 'poor compliers' in terms of age, disease duration, weight or E2 levels.

On the analysis of 'compliers' only, there were significant improvements in ESR at three months $(p=0.04)$, AI at three and six months $(p<0.01)$ and VPS at three and six months $(\mathrm{p}<0.05)$ compared with placebo (see figure). The nett effects of HRT, compared with placebo and, on baseline values of variables after six months of treatment were as follows: ESR $-8.9 \%$ (NS), EMS $-25 \cdot 2 \%$ (NS), AI $-28.9 \% \quad(p<0.01)$, VPS $-21.7 \% \quad(p<0.05)$ and VIS $+10 \cdot 4 \%$ (NS) (table 4 ).

When compared with 'poor compliers', significant improvements were seen in the 'compliers' at three months in AI $(p<0.001)$ and at six months in EMS $(p=0.001), A I$ $(p<0.001)$ and VPS $(p=0.05)$.

During the six month period of study, no alterations in concomitant RA therapy. were made in 72 patients $(79 \%)$ taking placebo and 60 patients $(78 \%)$ taking HRT, alterations being similar in placebo and both HRT groups.

No differences were noted in response to therapy comparing the women who had had hysterectomy (receiving E2 only) and those who had not (receiving E2) and norethisterone). Patients who were less or more than five years from the menopause did not respond differently to treatment. In the overall HRT group, there were no significant correlations between E2 levels and changes in disease activity. 
Table 1 Characteristics of HRT and placebo groups

\begin{tabular}{lccc}
\hline & \multicolumn{1}{l}{$H R T$} & \multirow{2}{*}{ Placebo } \\
\cline { 2 - 3 } & All & Compliers & \\
\hline Number (mean, SD) & 77 & 42 & 91 \\
Age (years) & $56 \cdot 2(5 \cdot 4)$ & $56 \cdot 8(5 \cdot 3)$ & $56 \cdot 0(4 \cdot 6)$ \\
Menopausal years & $7 \cdot 7(5 \cdot 7)$ & $8 \cdot 5(6 \cdot 5)$ & $8 \cdot 1(5 \cdot 9)$ \\
Disease duration (years) & $11 \cdot 6(10 \cdot 5)$ & $10 \cdot 2(8 \cdot 4)$ & $12 \cdot 2(9 \cdot 2)$ \\
Oestradiol (pmol/l) & $73 \cdot 0(148 \cdot 1)$ & $74 \cdot 9(133 \cdot 0)$ & $60 \cdot 8(136 \cdot 2)$ \\
ESR (mm/hr) & $33 \cdot 7(24 \cdot 0)$ & $38 \cdot 3(25 \cdot 7)$ & $34 \cdot 8(23 \cdot 9)$ \\
AI (0-84) & $10 \cdot 5(8 \cdot 2)$ & $12 \cdot 2(8 \cdot 5)$ & $11 \cdot 7(9 \cdot 3)$ \\
VPS (cms) & $4 \cdot 2(2 \cdot 6)$ & $4 \cdot 6(2 \cdot 6)$ & $4 \cdot 4(2 \cdot 7)$ \\
EMS (mins) & $33 \cdot 2(36 \cdot 4)$ & $40 \cdot 4(39 \cdot 6)$ & $49 \cdot 7(49 \cdot 9) \star$ \\
HAQ (0-3) & $1 \cdot 54(0 \cdot 9)$ & $1 \cdot 43(0 \cdot 92)$ & $1 \cdot 52(1 \cdot 05)$ \\
Steroid users & $19(20 \cdot 9 \%)$ & $9(21 \cdot 4 \%)$ & $16(20 \cdot 8 \%)$ \\
\hline
\end{tabular}

*difference placebo $v$ HRT (all); $\mathrm{p}=0.02$.

Table 2 Patients failing to complete study

\begin{tabular}{lcl}
\hline & $H R T$ & Placebo \\
\hline Withdrew & 15 & 6 \\
$\quad$ cancer scare & 4 & \\
artificial periods & 3 & \\
GP advised against HRT & 1 & 6 \\
Others & 7 & 1 \\
Moved area & 2 & 0 \\
Side effects & 5 & \\
pre-menstrual syndrome & 4 & 1 \\
hypertension & 1 & 1 \\
Died & 1 & 9 \\
Other & 23 & 90.1 \\
\hline
\end{tabular}

Table 3 Comparison of the effect of treatment in HRT and placebo groups

\begin{tabular}{|c|c|c|c|c|}
\hline & & $\begin{array}{l}H R T \\
\text { (mean change, SE) }\end{array}$ & $\begin{array}{l}\text { Placebo } \\
\text { (mean change, SE) }\end{array}$ & $p$ value \\
\hline ESR & 3 & $-0.7(2.4)$ & $+3.3(3.7)$ & 0.2 \\
\hline$(\mathrm{mm} / \mathrm{hr})$ & 6 & $-0.8(2 \cdot 7)$ & $+0.6(2.2)$ & 0.7 \\
\hline EMS & 3 & $+8.1(6.9)$ & $-3.9(4 \cdot 3)$ & 0.1 \\
\hline (mins) & 6 & $-0.5(6.3)$ & $-3.8(5 \cdot 1)$ & 0.6 \\
\hline AI & 3 & $-1 \cdot 1(0 \cdot 6)$ & $-0.3(0.6)$ & 0.3 \\
\hline & 6 & $-1 \cdot 7(0 \cdot 8)$ & $-0.4(0.8)$ & $0 \cdot 3$ \\
\hline VPS & 3 & $-0 \cdot 4(0 \cdot 3)$ & $+0 \cdot 3(0 \cdot 3)$ & 0.07 \\
\hline$(\mathrm{cms})$ & 6 & $-0.5(0.3)$ & $+0 \cdot 0(0.3)$ & 0.3 \\
\hline & 3 & $+0.37(0 \cdot 14)$ & $+0 \cdot 20(0 \cdot 15)$ & 0.4 \\
\hline (cms) & 6 & $+0.56(0.19)$ & $+0.19(0.18)$ & $0 \cdot 2$ \\
\hline
\end{tabular}

Table 4 The effect of treatment in complier HRT group compared with placebo at three and six months

\begin{tabular}{|c|c|c|c|c|c|c|}
\hline & & $\begin{array}{l}\text { Compliers } \\
\text { (mean change, SE) }\end{array}$ & $\begin{array}{l}\text { Placebo } \\
\text { (mean change, SE) }\end{array}$ & $\begin{array}{l}\text { Effect of } \\
\text { treatment }\end{array}$ & $\begin{array}{l}\text { Nett \% } \\
\text { effect of } \\
\text { treatment }\end{array}$ & $p$ value \\
\hline ESR & months 3 & $-4 \cdot 7(3 \cdot 1)$ & $+3 \cdot 3(2 \cdot 2)$ & $-7 \cdot 7$ & & 0.04 \\
\hline$(\mathrm{mm} / \mathrm{hr})$ & 6 & $-2.7(3.3)$ & $+0.6(2.2)$ & $-3 \cdot 4$ & -9.9 & 0.4 \\
\hline EMS & 3 & $+8.7(11.9)$ & $-3 \cdot 9(4 \cdot 3)$ & $+12 \cdot 6$ & & $0 \cdot 3$ \\
\hline (mins) & 6 & $-14 \cdot 1(6 \cdot 3)$ & $-3 \cdot 8(5 \cdot 1)$ & $-10 \cdot 2$ & $-27 \cdot 2$ & $0 \cdot 2$ \\
\hline \multirow{2}{*}{ AI } & 3 & $-3.0(0.7)$ & $-0 \cdot 3(0 \cdot 6)$ & $-2 \cdot 7$ & & 0.006 \\
\hline & 6 & $-3.9(0.9)$ & $-0.4(0.8)$ & $-3 \cdot 5$ & $-29 \cdot 3$ & 0.004 \\
\hline VPS & 3 & $-0.9(0.3)$ & $+0.3(0.3)$ & $-1 \cdot 2$ & & 0.004 \\
\hline (cms) & 6 & $-1.0(0 \cdot 3)$ & $0.0(0.3)$ & $-1 \cdot 0$ & $-21 \cdot 0$ & 0.04 \\
\hline VIS & 3 & $+0.44(0.21)$ & $+0.20(0.15)$ & $+0 \cdot 22$ & & $0 \cdot 3$ \\
\hline$(\mathrm{cms})$ & 6 & $+0.71(0.23)$ & $+0.19(0.18)$ & +0.52 & $+10 \cdot 4$ & 0.07 \\
\hline
\end{tabular}

\section{Discussion}

The beneficial effects of HRT have been established in the context of cardiovascular disease and osteoporosis ${ }^{21-23}$ and HRT may also be valuable in the management of perimenopausal rheumatic symptoms, such as carpal tunnel syndrome. ${ }^{24}$ Early studies of oestrogen replacement in arthritis showed responses in an array of rheumatic complaints, particularly those following oophorectomy. ${ }^{13-14}$ In 1966 Demers et al reported on 44 patients with RA treated with Enovid (mestranol and norethinodryl combination) and found an improvement in the disease activity in those
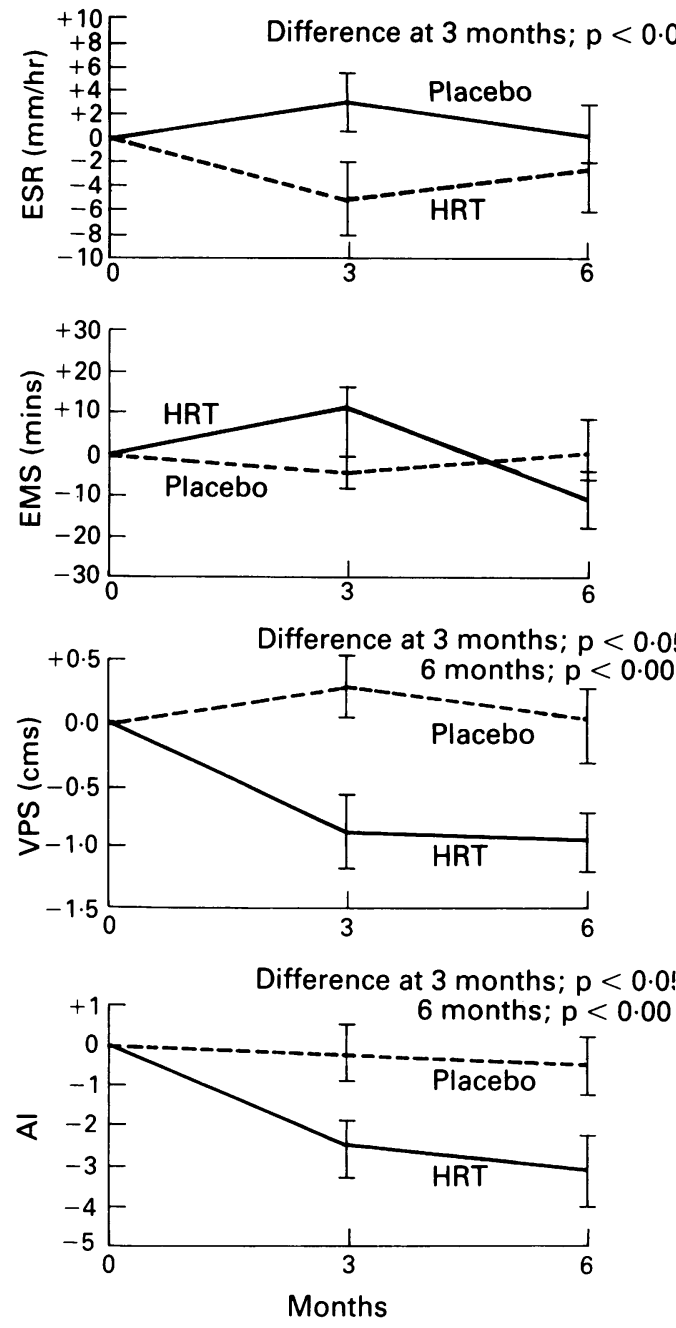

Changes in disease activity variables; HRT compliers v placebo (mean values with standard error).

able to tolerate the drug. ${ }^{15}$ More recently, Bijlsma et al examined 10 women with active $\mathrm{RA}$ in a cross over trial of ethinyloestradiol $12.5 \mu \mathrm{g}$ daily, given for 12 weeks. ${ }^{17}$ During oestrogen replacement there were only significant improvements in 30 metre walking time and haemoglobin levels. There was a reduction in the number of swollen joints but a rise in joint tenderness. Van den Brink et al reported a double blind controlled study of oestradiol valerate $2 \mathrm{mg}$ daily in 40 postmenopausal patients and found no improvement in articular index, pain score, HAQ or ESR. E2 levels were not given. ${ }^{18}$

To our knowledge, this is the largest randomised prospective study of the effect of HRT in RA. There was no overall effect of HRT, but a subgroup of patients who achieved high serum E2 levels exhibited clinically relevant reductions in VPS $(22 \%)$ and AI $(29 \%)$ after six months as well as non significant reductions in ESR (9\%) and EMS (25\%) compared with placebo. Similar improvements were seen in disease parameters comparing 'compliers' with 'poor-compliers', supporting a possible therapeutic effect of HRT. It should be stressed that these results were obtained in patients taking other disease modifying drugs which may have partly obscured the true effect of HRT. A total of $58 \%$ of patients allocated to HRT failed to 
achieve E2 levels of over $100 \mathrm{pmol} / /$ either because of known early withdrawal $(23 \%)$ or probable poor-compliance $(35 \%)$. We have assumed that inadequate compliance was the principle reason for suboptimal E2 levels in 35 patients, although other factors, including poor drug absorption and drug interactions, may be important. 'Poor compliers' may represent a failure to respond to HRT. Such patients may also be poor compliers of concurrent antirheumatic therapies although we have no evidence for this; there were similar numbers receiving SAARDs and steroids in each group at study entry and completion. Compliance with HRT is notoriously poor and Ryan et al found that of 400 women from the London region advised to take HRT on the basis of low bone density, $40 \%$ reported discontinuing treatment after 6-12 months ${ }^{25}$ and genuine compliance may be still lower. Low compliance rates underline the importance of careful patient monitoring, probably with serum E2 levels, in HRT trials.

The substantial differences in mean serum E2 levels between 'compliers' and 'poorcompliers' suggests that quite high E2 levels may be necessary to achieve an effect on disease activity and further studies using higher dose HRT would be useful.

Potential bias due to the single 'blind' design needs to be addressed. Subjects may have felt better for the known effects of HRT on mood swings, sleep pattern and lethargy and this may partly account for improved subjective measures. Although patients were only informed of the potential effects of HRT on bone metabolism and not on their RA, some may have hoped for an anti-rheumatic effect of HRT resulting in biased pain scores and EMS. Improvements in the objective measures, AI and ESR, cannot be explained on these grounds alone and the results point towards a possible effect of oestrogen in RA. Observer bias has been reduced by the comparison between 'complier' and 'non-complier' groups using retrospective analysis of serum E2 levels. A double blind study with a 'dummy' placebo would have been theoretically preferable but would have been disadvantaged by the ethical and practical difficulties of enforcing a menstrual bleed in the placebo groups.

A possible effect of HRT in RA is supported by the results of the animal studies of Holmdahl et al. Type II collagen induced arthritis in female mice was exacerbated by castration but subsequent E2 treatment ameliorated the arthritis and depressed $T$ cell activity against type II collagen. ${ }^{89}{ }^{26}$ Mattson et al have since shown that treatment of the same animal model with oestradiol post partum will protect against the characteristic flare of arthritis. ${ }^{27}$

Potential mechanisms behind these observations include the effects of oestrogen on T-cell function, cytokine production, neutrophil function, the thymus and putative interactions with heat-shock proteins..$^{28-37}$ Interactions of oestrogens on T-cell function is clearly important in RA. The suppressor effect of human CD8 $\mathrm{T}$ cells has been shown to be inhibited by $\mathrm{E} 2^{29}$ and oestrogen receptors have been reported on $\mathrm{CD} 8$ but not $\mathrm{CD} 4$ cells. ${ }^{30} \mathrm{~A}$ plausible explanation for a therapeutic action with HRT lies in the effects of the menopause on the activity of the inflammatory cytokine, IL-1. Pacifici et al have shown that IL-1 release from monocytes rises after the menopause and this is in turn suppressed within one month with HRT. ${ }^{12}$ This may be effected through cortisol, since oestrogen administration can elevate levels of cortisol, ${ }^{38-39}$ itself a proven suppressor of IL-1 activity. ${ }^{40-41}$

The effects of oestrogens on immune and inflammatory mechanisms are complex but reports suggest that oestrogens can suppress inflammatory arthritis. This study failed to show an ameliorating effect of HRT in postmenopausal RA when used as an adjunct therapy but identified a subgroup of responders who had higher serum E2 levels. Further therapeutic studies should be encouraged that assess the direct, rather than complimentary, effects of oestrogens in RA, perhaps using higher doses. RA is associated with an increased risk of osteoporotic fracture ${ }^{42}$ but if future studies confirm the bone preserving effect of HRT in RA, ${ }^{43}$ then HRT can be prescribed without fear of a disease flare.

We thank all the patients involved in the study and the respective clinicians who allowed their recruitment: Dr D L Scott and Dr J E Dacre, The Homerton Hospital, London E9; Dr D V Doyle and Dr J Lanham, Whipps Cross Hospital, Leytonstone, London E1 1; Dr A J Griffin and Dr A S M Jawad, Chase Farm Hospital, Enfield, Middlesex; Dr C G Barnes, Dr J D Perry and Dr B L Kidd, The Royal London Hospital, London E1; Dr P W Thompson, Poole General Hospital, Poole, Dorset. We are grateful for the sex hormone measurements by Dr L Perry, Department of Reproductive Physiology, St Bartholomew's Hoppital and for assistance with statistical analysis from $\mathrm{Mr} \mathrm{T}$ Nguyen. This study was partly funded by a grant from CibaGeigy (UK)

1 Oka M, Vaino U. Effect of pregnancy on the prognosis and serology of rheumatoid arthritis. Acta Rheum Scand 1966; 12: $47-52$.

2 Ostensen M, Aure B, Husby G. Effects of pregnancy and hormonal changes on the activity of rheumatoid arthritis. Scand f Rheumatol 1983; 12: 69-72.

3 Pope R M, Yoshinoya S, Rutstein J, Persellin R H. Effects of pregnancy on the prognosis and serology of rheumatoid arthritis. Am f Med 1983; 74: 973-9.

4 Spector T D, Hochberg M C. The protective effect of the oral contraceptive pill on rheumatoid arthritis: an overview of the analytic epidemiological studies using overview of the analytic epidemiological studies using
meta analysis. Fournal of Clin Epidemiology 1990; 43: $1221-30$

5 Duthie J J R, Brown P E, Truelove L H, Barager F D, Lawrie A J. Prognosis in rheumatoid arthritis; a further report. Ann Rheum Dis 1964; 23: 193-202.

6 Rasker J J, Cosh J A. The natural history of rheumatoid arthritis: a fifteen year follow up study. The prognostic significance of features noted in the first year. Clin Rheumatol 1984; 3: 11-20.

7 Sherrer Y S, Bloch D A, Mitchell D M, Young D Y, Fines JF. The development of disability in rheumatoid arthritis. JF. The development of disability in
Arthritis Rheum 1986; 29: 494-500.

8 Holmdahl R, Jansson L, Anderson M. Female sex hormones suppress development of collagen induced arthritis in mice. Arthritis Rheum 1986; 29: 1501-9.

9 Holmdahl R, Jansson L, Meyerson B, Khareskog L. Oestrogen induced suppression of collagen arthritis: 1 . Longterm oestradiol treatment of DBA/1 mice reduces severity and incidence of arthritis and decreases the antitype II collagen immune response. Clin Exp Immunol 1987; 70: 372-8.

10 Paavonen T, Anderson L C, Adlercreutz H. Sex hormone regulation of in vitro immune response. Estradiol enhances B-cell maturation via inhibition of suppressor T-cells in pokeweed-mitogen stimulated cultures. $f$ Exp Med 1981; 154: 1935-45.

11 Cohen J H M, Danel L, Cordier G, Saez S, Revillard J P. Sex steroid receptors in peripheral T-cells: absence of androgen receptors and restriction of oestrogen receptors

to OKT8 positive cells. $\mathcal{f}$ Immunol $1983 ; 131: 2707-11$.
12 Pacifici R, Rifas L, McCracken R, et al. Ovarian steroid 
treatment blocks a postmenopausal increase in blood monocyte interleukin-1 release. Proc Natl Acad Sci 1989, 86: $2398-402$.

13 Hall F C. Menopausal arthralgia. N Engl f Med 1938; 219: 1015-26.

14 Cohen A, Dubbs A W, Myers A. The treatment of atrophic arthritis with estrogenic substance. $N$ Engl f Med 1940 222: $140-2$

15 Demers R, Blais J A, Pretty H. Arthrite rheumatoide traitee par norethynodrel associee a mestranol. Aspects clinique et tests de laboratoire. Canadian Medical Association 1966; 95: $350-4$.

16 Gilbert M, Rotstein J, Cunningham C, Estrin I, Davidson A, Pincus $\mathrm{G}$. Norethynodrel with mestranol in treatment of rheumatoid arthritis. JAMA 1964; 190: 235

17 Bijlsma J W J, Huber-Bruning O, Thijssen J H H. Effect of oestrogen treatment on clinical and laboratory manifestations of rheumatoid arthritis. Ann Rheum Di 1987; 46: 777-9.

18 van den Brink $H$ R, van Everdingen $A$, van Wijk $M J G$, Jacobs J W G, Bijlsma J W J. Adjuvant estrogen therapy has no effect on disease activity in postmenopausal women with active rheumatoid arthritis. Arthritis Rheum 1992; 35: S202.

19 Selby P L, Peacock M. Dose dependent response of symptoms, pituitary and bone to transdermal oestrogen in postmenopausal women. BMF 1986; 293: 1337-9.

20 Powers M S, Schenkel L, Darley P E, Good W R, Balestra J C. Pharmacokinetics and pharmacodynamics of transdermal dosage forms of $17 \mathrm{~B}$-estradiol: comparison with conventional oral estrogens used for hormon replacement. Am f Obstet Gynaecol 1985; 152: 1099-106.

21 Stampfer M J, Colditz G A. Estrogen replacement therap and coronary heart disease: a quantitative assessment of the epidemiological evidence. Prev Med 1991; 20: 47-63.

22 Hutchinson T A, Polansky S M, Feinstein A R. Post menopausal oestrogens protect against fracture of hip and menopausal oestrogens protect again

23 Paganini-Hill A, Ross R K, Gerkins V R, Henderson B E, Arthur M, Mack T M. Menopausal estrogen therapy and hip fractures. Ann Int Med 1981; 95: 28-31.

24 Hall G M, Spector T D, Studd J W W. Carpal tunnel syndrome and hormone replacement therapy. BMF 1992 304:382.

25 Ryan P J, Harrison R, Blake G M, Fogelman I. Compliance with hormone replacement therapy (HRT) after screening for postmenopausal osteoporosis. Br 7 Obstet Gynecol 1992; 99: 325-28.

26 Holmdahl R, Carlsten H, Jansson L, Larsson P. Oestrogen is a potent immunomodulator of murine experimental is a potent immunomodulator of murine experim

27 Mattson R, Mattson A, Holmdahl R, Whyte A, Rook G A. Maintained pregnancy levels of oestrogen afford complete protection from post partum exacerbation of collage induced arthritis. Clin Exp Immunol 1991; 85: 41-47.

28 Da Silva J A P. Heat shock proteins: the missing link between hormonal and reproductive factors and rheumatoid arthritis. Ann Rheum Dis 1991; 50: 735-39.

29 Paavonen T, Andersson L C. The estrogen antagonists, tamoxifen and FC-1157a, display estrogen like effects on tamoxifen and FC-1 f human lymphocyt

30 Stimson $\mathrm{W}$ H. Oestrogen and human T-lymphocytes. Presence of specific receptors in the T-suppressor cytotoxic subset. Scan f Immunol 1988; 28: 345-50.

31 Pfeiffer $\mathrm{R}$ W, Patterson R M. Modulation of lectin stimulated lymphocyte agglutination and mitogenesis by estrogen metabolites; effects on early events of lymphocyte activation. Arch Toxicol 1985; 58: 157-64

32 Seaman W E, Blackman W A, Grindhart T D, Roubinian J R, Loels J M, Talal N. Beta estradiol reduces natural killer cells in mice. 7 Immunol 1978; 121: 2193-8.

33 Screpanti I, Santori A, Gulino A, Heberman R B, Frati L. Estrogen and anti-estrogen modulation of the levels of mouse natural killer activity and large granular lymphocytes. Cell Immunol 1987; 106: 191-202.

34 Luster M I, Hayes H T, Korach K, et al. Estrogen immunosuppression is regulated through estrogenic responses in the thymus 7 Immunol 1984; 133: 110-16.

35 Weusten J J A M, Blankenstein M A, Thijssen J Ha, et al. Presence of oestrogenic receptors in human blood mononuclear cells and thymocytes. Acta Endocrinol 1986; 112: 409-14.

36 Stimson W H, Hunter I C. Estrogen induced immunoregulation mediated through the thymus. I Clin Lab Immunol 1980; 4: 27-33

37 Buyon J P, Korchak H M, Rutherford L E, Ganguly M Weissman G. Female hormones reduce neutrophil responsiveness in vitro. Arthritis Rheum 1984; 27 $623-30$

38 Tazuke S, Khaw K-T, Barrett-Connor E. Exogenous estrogen and endogenous sex hormones. Medicine 1992; 71: $44-51$

39 Lobo R A, Goebelsmann U, Brenner P, Mischell D. The effects of estrogen on adrenal androgens in estrogen on adrenal androgens in oophorect $471-8$.

40 Chensue L, Terebuh P D, Remick D G, Scales W E, Kunke $\mathrm{S}$ C. In vivo biologic and immunochemical analysis of interleukin 1 alpha, beta and tumor necrosis factor durin experimental endotoxaemia. Kinetics, Kupffer cell expression and glucocorticoid effects. Am f Pathol 1991; 138: $395-402$

41 Dinarello C A. Interleukin 1 and interleukin antagonism. Blood 1991; 77: 1627-652.

42 Spector T D, Hall G M, McCloskey E V, Kanis J. The prevalence of vertebral fractures in postmenopausal prevalence of vertebral fractures in postm

43 Van den Brink H R, Lems W F, Van Everdingen A A, Bijlsma J W J. Adjuvant oestrogen treatment increases bone mineral density in postmenopausal women with rheumatoid arthritis. Ann Rheum Dis 1993; 52: 302-5. 